\title{
Model Materials for Reactor Pressure Vessel
}

\author{
J. Degmová ${ }^{a, *}$, L. Debarberis ${ }^{b}$ And V. KRŠJAK ${ }^{b}$ \\ ${ }^{a}$ Department of Nuclear Physics and Technology, Faculty of Electrical Engineering and Information Technology, \\ Slovak University of Technology, Ilkovičova 3, 81219 Bratislava, Slovakia \\ ${ }^{b}$ JRC-IE, Joint Research Centre, Institute for Energy, P.O. Box 2, Petten 1755 ZG, The Netherlands
}

\begin{abstract}
In this paper we report preliminary results from a study focused on investigation of the role of elements as $\mathrm{Cr}$, $\mathrm{Ni}, \mathrm{Mn}$ and $\mathrm{Si}$ in the radiation stability of reactor pressure vessel steels. Twelve model ferritic steels and eight model welds with basic composition derived from Russian VVER-1000 and Western PWR reactor pressure vessel materials were studied by magnetic Barkhausen noise and Charpy-V impact measurements. Comparison of these two model materials led to the conclusion that the ductile-brittle transition temperatures and Barkhausen noise RMS values of model steels are shifted to the lower values as those of model welds. The VVER-1000 as reference point is shifted to lower RMS values in comparison with model steels and model welds. The next stage of the assessment will involve the investigation of the radiation effect on the model steels with accumulated neutron fluence of $10^{19} \mathrm{n} / \mathrm{cm}^{2}$.
\end{abstract}

PACS numbers: 28.41.Qb, 62.25.Mn, 75.50.Cc, 81.70.Bt, 81.70.Ex

\section{Introduction}

Reactor pressure vessel (RPV) embrittlement represents one of the limiting factors of today's nuclear power plant (NPP) lifetime. Due to the need of NPP lifetime extension as well as increase of passive safety, the investigation of the microstructural changes in the RPV-steels during long-term operation should have the highest priority [1]. It has been found that some deleterious elements may cause synergy effect in producing the complex radiation defects which can lead to the radiation-induced degradation in the mechanical properties of RPV steels [2]. The problem is rather complex and it is still the subject of large international programs [3-5]. In order to understand the role and influence of $\mathrm{Ni}, \mathrm{Si}$, $\mathrm{Cr}$ and $\mathrm{Mn}$ as alloying elements on the mechanical properties of steels, a large spectrum of ferritic steels with parametric variation of alloying elements, as well as impurities content, were designed. As a result, 12 model steel and 8 model welds were derived from VVER-1000 materials and some western PWR RPV materials.

\section{Experimental}

The nominal base compositions of the 12 model steels are derived from typical Russian and Western RPV base metal materials. The nominal base compositions of 8 model welds were derived from typical SV12Ch2N2MAA weld with variation of certain elements as $\mathrm{Ni}, \mathrm{Si}, \mathrm{Cr}$ and Mn (see Table).

\footnotetext{
* corresponding author; e-mail: jarmila.degmova@stuba.sk
}

Impact Testing Hammer WOLPERT PW 5 (50 J) equipped by ISO $10 \mathrm{KN}$ tup was used to test miniaturised Charpy V-notch samples (KLST of dimensions $3 \times 4 \times 27.5 \mathrm{~mm})$. Testing was prepared in the temperature range from -150 up to $150^{\circ} \mathrm{C}$. The temperature criteria for KLST specimen used for ductile-brittle transition temperatures (DBTT) determination were 1.9 or $3.1 \mathrm{~J}$.

The Barkhausen analysis was carried out using a commercial system Stresstech AST $\mu$ Scan 500. For the Barkhausen excitation a sinusoidal exciting magnetic field with magnetizing voltage of $10 \mathrm{~V}_{p p}$ was used. The signal of the pick-up coil was processed by a $5-500 \mathrm{kHz}$ band pass filter and amplified with a gain of 20. The applied magnetizing frequency was $10 \mathrm{~Hz}[6]$. The root mean square (RMS) values were calculated by averaging the results from two measurements from each side of the notched KLST sample. The RMS value is simply a generic parameter that is calculated from a complete cycle of the Barkhausen emission and is calculated as follows (where $x_{i}$ is the value corresponding to individual signal):

$$
\mathrm{RMS}=\sqrt{\frac{1}{n}} \sum_{i=0}^{n-1} x_{i}^{2}
$$

\section{Results and discussion}

The results obtained on 12 model steels are summarised in Table. The range of DBTT differs between high $\mathrm{Cr}(\mathrm{Cr}>2$ mass\%) and low $\mathrm{Cr}(\mathrm{Cr}<2$ mass\%) containing steels. When for high $\mathrm{Cr}$ containing steels the DBTT's range from $-150^{\circ} \mathrm{C}$ to $-129^{\circ} \mathrm{C}$, in the case of low $\mathrm{Cr}$ containing steels the DBTT's range is wider, 
TABLE

$\mathrm{Si}, \mathrm{Mn}, \mathrm{Cr}$ and $\mathrm{Ni}$ content for model steels (samples 631-304) and models welds (A-H) focused on the content of 4 most important elements.

\begin{tabular}{c|c|c|c|c|c|c}
\hline \hline ID & $\begin{array}{c}\mathrm{Si} \\
{[\%]}\end{array}$ & $\begin{array}{c}\mathrm{Mn} \\
{[\%]}\end{array}$ & $\begin{array}{c}\mathrm{Cr} \\
{[\%]}\end{array}$ & $\begin{array}{c}\mathrm{Ni} \\
{[\%]}\end{array}$ & $\begin{array}{c}\mathrm{DBTT} \\
{\left[{ }^{\circ} \mathrm{C}\right]}\end{array}$ & $\begin{array}{c}\mathrm{RMS} \\
{[\mathrm{V}]}\end{array}$ \\
\hline 631 & 0.28 & 0.43 & 2.22 & $<0.02$ & -150 & 8.51 \\
632 & 0.26 & 0.38 & 2.19 & 0.99 & -160 & 8.36 \\
633 & 0.24 & 0.38 & 2.13 & 2.00 & -129 & 7.80 \\
634 & 0.23 & 0.83 & 2.13 & 2.00 & -142 & 7.40 \\
641 & 0.33 & 0.77 & 2.16 & 1.02 & -150 & 7.64 \\
642 & 0.33 & 1.37 & 2.15 & 1.02 & -137 & 7.38 \\
643 & 0.32 & 1.36 & 2.06 & 1.99 & -141 & 7.58 \\
644 & 0.51 & 1.31 & 2.07 & 2.00 & -112 & 7.57 \\
301 & 0.35 & 0.78 & 0.10 & 0.58 & -131 & 5.99 \\
302 & 0.35 & 0.77 & 0.08 & 0.96 & -150 & 6.86 \\
303 & 0.37 & 0.74 & 0.09 & 1.90 & -150 & 7.08 \\
304 & 0.33 & 1.27 & 0.07 & 1.97 & -104 & 6.65 \\
$(\mathrm{~A})$ & 0.18 & 0.57 & 2.07 & 1.30 & -3 & 5.0 \\
$(\mathrm{~B})$ & 0.31 & 0.56 & 2.04 & 1.59 & -16 & 7.9 \\
(C) & 0.32 & 0.60 & 1.95 & 1.87 & -50 & 6.9 \\
(D) & 0.29 & 0.72 & 2.01 & 1.57 & -8 & 7.9 \\
(E) & 0.30 & 0.89 & 2.00 & 1.94 & -16 & 11.4 \\
(F) & 0.29 & 1.07 & 2.04 & 1.26 & -24 & 9.6 \\
(G) & 0.30 & 1.07 & 2.04 & 1.57 & -21 & 8.1 \\
(H) & 0.32 & 1.08 & 1.98 & 1.89 & 73 & 7.2 \\
& & & & & &
\end{tabular}

from $-150{ }^{\circ} \mathrm{C}$ to $-104^{\circ} \mathrm{C}$. The lowest value of DBTT is reached for several different compositions, where one can find combination of very low $\mathrm{Ni}$ content with high $\mathrm{Cr}$ and low Mn content (631) but also very low $\mathrm{Cr}$ content with quite high $\mathrm{Ni}$ and middle range of $\mathrm{Mn}$ content (303). Generally, the results imply that beside $\mathrm{Cr}$ no other elements have significant influence on the DBTT values.

The RMS values show (see Table) that in this case the amount of $\mathrm{Cr}$ plays an important role i.e. an increase of $\mathrm{Cr}$ content in model steels leads to an increase of RMS values independently of $\mathrm{Mn}$ and Si content. From Table it can be seen that also the percentage of $\mathrm{Ni}$ has influence on RMS values. The RMS value of material designated as 631 with less than 0.02 mass\% of $\mathrm{Ni}$ in combination with quite high percentage of $\mathrm{Cr}$ (about 2.22 mass\%) is the highest one $(8.51 \mathrm{~V})$. The second highest value of RMS is obtained for material 632 with high $\mathrm{Cr}$ content (about 2.19 mass\%) and with just average percentage of $\mathrm{Ni}$ (about 0.99 mass\%). The lowest value was measured from designated as 304 combining low $\mathrm{Cr}$ content (0.07 mass\%) with quite high Ni (1.97 mass\%) and Mn (1.27 mass\%) content.

Table shows the RMS values of the realistic welds. It can be seen that the low Si content $(=0.18 \%)$ significantly decreases the RMS values. These values achieve approximately half of the values characteristic for the welds with higher $\mathrm{Si}$. On the contrary, the variation of Mn composition in the range from 0.57 to 1.08 mass\% seems to have no significant influence on RMS values. The effect of $\mathrm{Cr}$ content is visible only in the case of its highest tested percentage, which is 2.07 mass $\%$ of $\mathrm{Cr}$ in the weld. The RMS values decreased almost to their half in comparison with the values characteristic for lower $\mathrm{Cr}$ content.

In the case of $\mathrm{Ni}$, the results of $\mathrm{BN}$ measurements are quite scattered and it is very difficult to distinguish the $\mathrm{Ni}$ effect [7]. The DBTT values are mostly from temperature range -2 to $-50^{\circ} \mathrm{C}$, only DBTT of sample designated as $\mathrm{H}$ is significantly higher reaching $73^{\circ} \mathrm{C}$. This sample combines high mass\% of all 4 elements of interest (Mn, $\mathrm{Si}$, $\mathrm{Cr}$ and $\mathrm{Ni}$ ) An increase in the mass\% of $\mathrm{Si}$ and Mn leads to the significant decrease of DBTT with only exception for their highest concentrations i.e. $0.32 \%$ of Si and $1.08 \%$ of Mn. The DBTT values increase almost linearly with increasing $\mathrm{Cr}$ content. Only the concentration of $1.98 \%$ of $\mathrm{Cr}$ is an exception: in this case DBTT reaches its highest value: $73^{\circ} \mathrm{C}$. With increasing Ni content, a slight decrease of the DBTT values can be observed. Only the value measured for sample designated as $\mathrm{H}$ (where $\mathrm{Ni}$ content corresponds to 1.98 mass\%) is significantly higher $\left(73^{\circ} \mathrm{C}\right)[7]$.

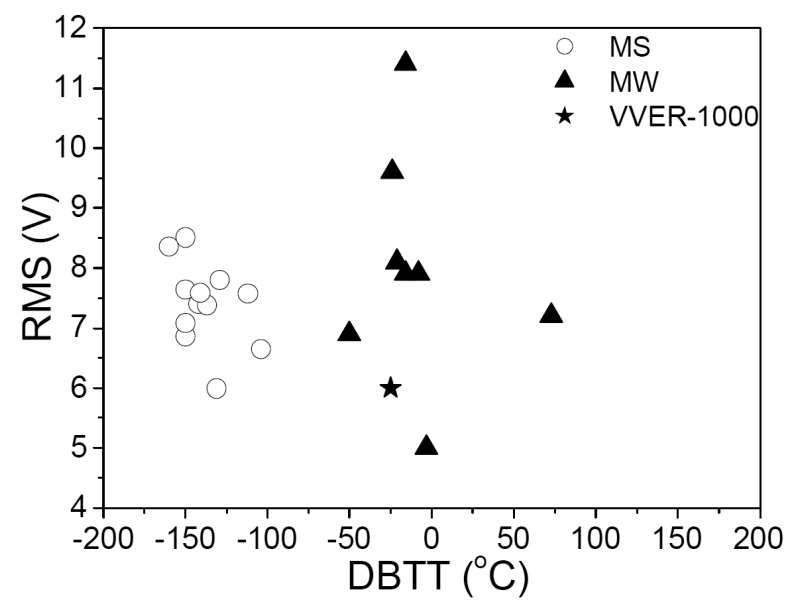

Fig. 1. RMS versus DBTT for model welds (MW) compared to the models steels (MS) at excitation frequency $10 \mathrm{~Hz}$. The empty circle is reference for VVER-1000 material $\left(\mathrm{DBTT}=-25^{\circ} \mathrm{C}, \mathrm{RMS}=6 \mathrm{~V}\right)$.

By comparing the RMS and DBTT values of the 8 realistic welds it is difficult to make a general conclusion since there is no common factor determining the evolution of the material microstructure. In as-received state of the material, there is no clear relation between these two values in every type of material. Figure 1 compares RMS versus DBTT of realistic welds with those of model steels and with reference material VVER-1000. In general, model steels combine lower DBTT with lower RMS whilst in the case of realistic welds the DBTTs and RMSs 
are higher in comparison with model steels. When we compare the results of model steels with our reference point, one can see that the position of the reference material is shifted to lower RMS in comparison with model steels and model welds. The neutron irradiation is expected to have significant influence on these correlations by comparison of DBTT shift with RMS values as a function of composition.

\section{Conclusions}

The set of model materials was fabricated in the aim to study the role of $\mathrm{Si}, \mathrm{Mn}, \mathrm{Cr}$ and $\mathrm{Ni}$ in the radiation stability of reactor pressure vessel steels. The results of two testing technique i.e. charpy impact and magnetic Barkhausen noise showed that in the as-cast state the element which mostly influences the mechanical and magnetic properties of tested materials is Cr. Comparison of the results from our tested model and reference VVER-1000 steel showed that the reference point is shifted to lower RMS in comparison with model steels and model welds.

\section{Acknowledgments}

This work was financially supported by VEGA$-1 / 0129 / 09$ and VEGA-1/0606/09.

\section{References}

[1] M.M. Ghoneim, F.H. Hammad, Int. J. Pres. Ves. Piping 74, 189 (1997).

[2] R.G. Odette, "ASTM STP 1046”, p. 343 (1990).

[3] Report IAEA, "Neutron Effects in Reactor Pressure Vessel Steels and Weldments", Working document Wien, Austria 1998.

[4] S. Jumel, J-P. Van Duysena, J. Nucl. Mater. 366, 256 (2007).

[5] L. Debarberis, U. von Estorff, S. Crutzen, M. Beers, H. Stamm, M.I. de Vries, G.L. Tjoa, Nucl. Eng. Design 195, 217 (2000).

[6] J. Degmova, L. Debarberis, EUR 22512 EN, The Netherlands 2006.

[7] J. Degmova, A. Rito-de-Abreau, T. Heftrich, H. Chantrain, L. Debarberis, EUR 22866 EN, The Netherlands 2007. 